\title{
Resistivity and heterogeneity of Earth crust in an active tectonic region, Southern Tuscany (Italy)
}

\author{
Adele Manzella \\ CNR-Istituto di Geoscienze e Georisorse, Pisa, Italy
}

\begin{abstract}
Southern Tuscany, belonging to the inner zone of the Northern Apennines, Italy, is an ideal laboratory for observing the physical features of the lithosphere and their evolution in tectonically active regions. Here the crust is very thin, with a thickness of less than $25 \mathrm{~km}$, and heat flow is very high, hence only very shallow depths of exploration are needed to investigate many of the middle-deep crustal features that are common to many other parts of the world. The magnetotelluric (MT) surveys performed in this region have provided information on the resistivity structure, which is related to the extent and distribution of free fluids and to the partial melts in the crust. The picture emerging from these MT surveys is that of a resistivity structure that is only partly related to the heat flow regime of the area. A very low resistivity was found below the vapour-dominated geothermal system of Larderello and below areas that have no clear connection to any geothermal system, whereas this reduction of resistivity is less conspicuous below the water-dominated geothermal system of Mt. Amiata.
\end{abstract}

Key words crustal exploration - magnetotellurics geothermal areas - Southern Tuscany

\section{Introduction}

The magnetotelluric (MT) method is used to estimate the electrical characteristics of Earth structures using naturally occurring electromagnetic fields. It is particularly suited to the task of exploring areas of high heat flow since these areas are commonly associated with dynamic activities such as magma emplacement, crustal fracturing, and the circulation of hot, electrically conductive fluids. Southern Tuscany, which is characterized by a high heat flow and the presence of two of the most important geot-

Mailing address: Dr. Adele Manzella, CNR-Istituto di Geoscienze e Georisorse, Via Moruzzi 1, 56124 Pisa, Italy; e-mail: manzella@igg.cnr.it hermal areas of the world, is an excellent test site for resistivity characterization. Indeed, Larderello has been studied in detail by MT soundings since 1973 (Fiordelisi et al., 1998; and references therein). For a long time MT surveys in Southern Tuscany region have encountered significant difficulties that mainly stem from three factors: i) the high level of electromagnetic signals from industrial and cultural sources, which interfere with the natural fields used in the method; ii) the presence of a very conductive shallow formation, and hence the need to acquire data for long periods; and iii) the naturally-occurring structural complexity commonly found in these areas, which requires two- or three-dimensional MT modelling for interpretation purposes, thus significantly increasing the amount of effort required by modelling. Apart from the uncorrelated noise that mainly affects the high frequencies linked to the wide variety of cultural noise common to all densely populated countries, an extremely coherent noise was found to be pervasive in the period 


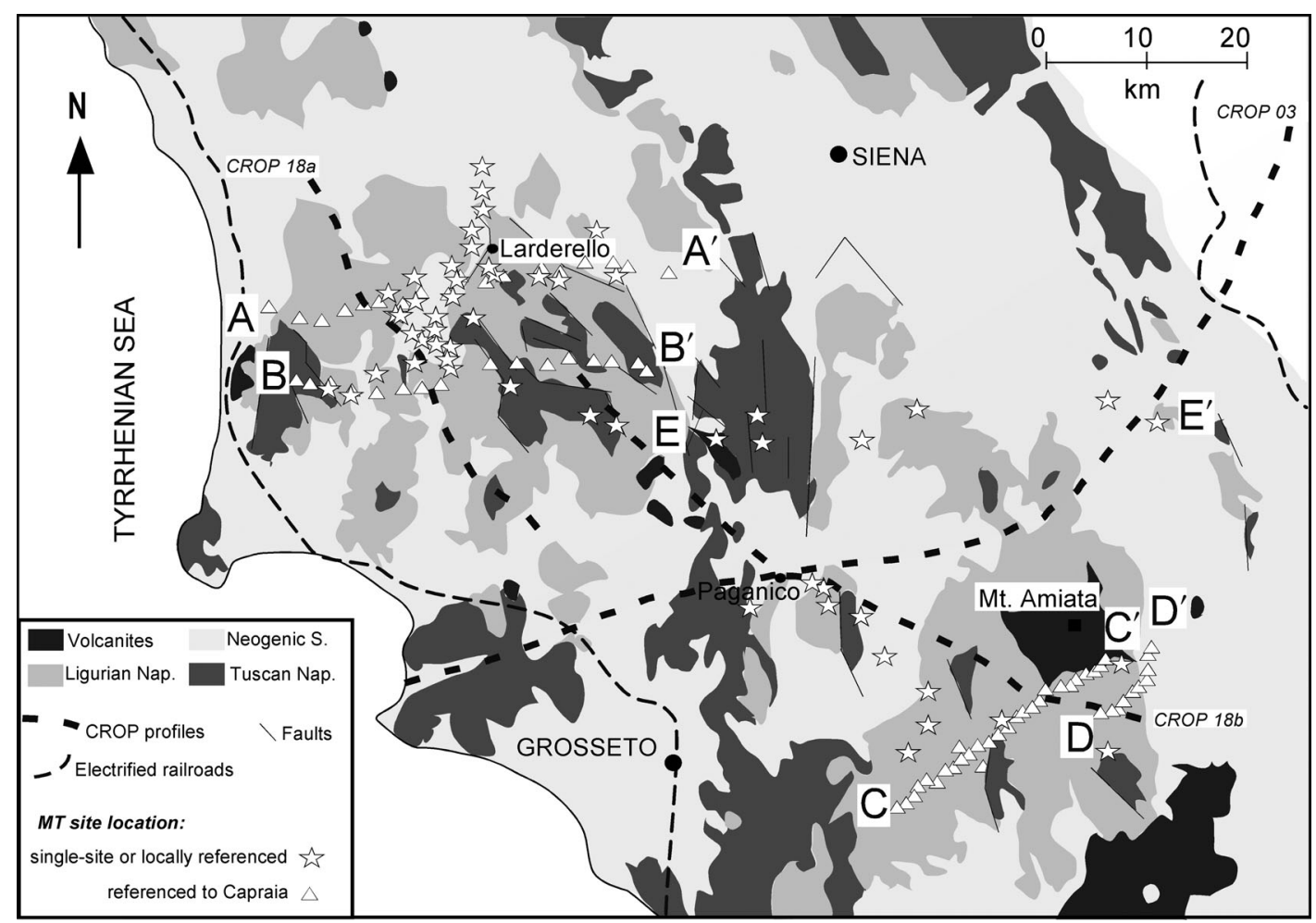

Fig. 1. Location of the magnetotelluric sites in a schematic geological map. The CROP profiles and the main electrified rail tracks are shown, and the main survey profiles are indicated by letters for reference in the text.

range of 1-1000 s. This noise, produced by the currents discharged by the direct-current electrified railways at the passage of trains, required considerable study and data processing (Fiordelisi et al., 1995; Larsen et al., 1996). The most recent MT surveys, however, have shown that in most areas this noise can be effectively removed and the data interpreted without distortion by using appropriate data acquisition and processing techniques. The continuous profiling technique was also used in the most recent surveys to increase the resolution of the shallower structure.

The MT surveys in Southern Tuscany were undertaken primarily for geothermal and deep crustal exploration (CROP, Deep Crust Exploration Projects) (De Angelis et al., 1998; Fiordelisi et al., 1998; Manzella et al., 1999).
The study area described in this paper is crossed by the CROP 03 and CROP 18 profiles (fig. 1). A total of 232 MT sites were acquired over the last 10 years, 108 of which were acquired for geothermal purposes and were referenced to a remote site on the island of Capraia in order to remove the extremely coherent electromagnetic noise. The remainder were single-site or locally referenced and many are affected by noise.

This paper describes the overall results obtained by modelling the entire set of data recorded after 1991. This gives a broad view of the deep electrical structure of the region, showing a conductive medium-low crust of regional scale but with some important exceptions that are not simply related to the geothermal systems. The interpretation of the MT data could provide some indication of the role played by 
electrical conductivity in the middle-lower crustal regimes.

\section{Geological background and geophysical outline}

Southern Tuscany belongs to the inner part of the Northern Apennines, and originated from the collision between the Corsica-Sardinia and Apulia microplates (Gianelli et al., 1997; and references therein). The region is characterised by NNW-SSE faults linked to the Alpine orogeny (fig. 2). After the post-Tortonian, prevalently extensional tectonics, the region underwent a general uplift, so that older units crop out in some places. Its extension was accompanied by anatectic magmatism whose ages decrease in an eastward direction. Shallow intrusive bodies are the heat sources of the two most important geothermal areas, Larderello and Mt. Amiata, which have undergone intensive exploratory and production drilling for almost half a century. Direct exploration by means of hundreds of shallow and deep wells has permitted to achieve a detailed reconnaissance of the first $4.5 \mathrm{~km}$ of the crustal structure. At Larderello drill-holes within the first $4.5 \mathrm{~km}$ of depth encountered sequences of sedimentary, metamorphic and igneous rocks. Below the Jurassic-to-Cenozoic ophiolite and flysch units (Ligurids) and a Triassic-to-Tertiary allochthonous unit (Tuscan Nappe), there is a zone of tectonic slices, involving Mesozoic rocks and Paleozoic formations. The deepest metamorphic units are micaschist and gneiss. Buried dykes, subvolcanic bodies of granite and thermo-metamorphic minerals were frequently crossed by deep drillings. The Mt. Amiata area, with respect to Larderello area, is characterised by the presence of lava flows covering the sedimentary sequence and by the particular nature of its basement, which is mostly made up of graphitebearing metasedimentary rocks.

The vapour-dominated geothermal system of Larderello and the water-dominated geothermal system of Mt. Amiata both consist of two reservoirs: a shallow reservoir within the carbonate units at $0.5-1 \mathrm{~km}$ depth, and a deeper, more extensive reservoir within the metamorphic basement, at depths of more than $2 \mathrm{~km}$ beneath the known geothermal fields, at pressures of up to 70 bar and temperatures between 300 and $350^{\circ} \mathrm{C}$ (Barelli et al., 2000; Fiordelisi et al.,

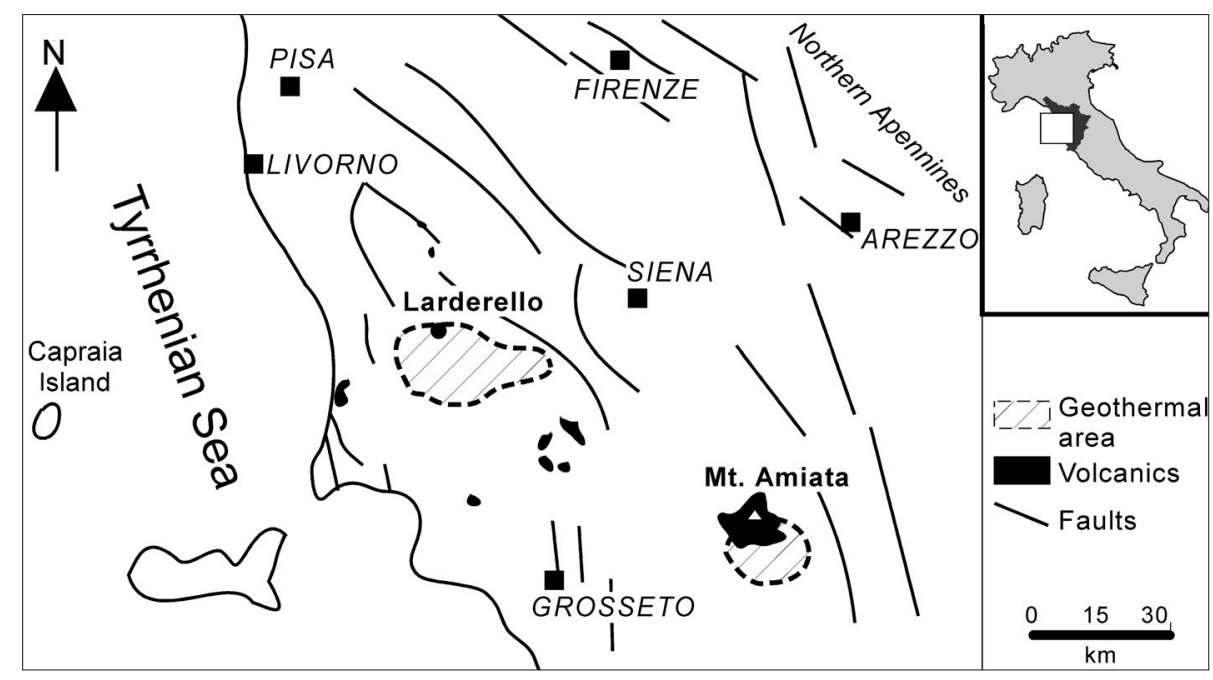

Fig. 2. Location map of Southern Tuscany, showing the geothermal areas and the main faults. 


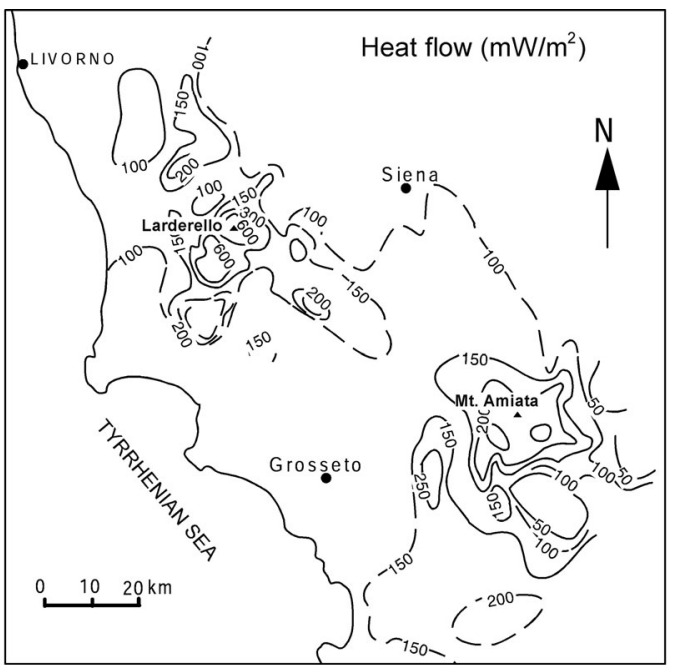

(a)

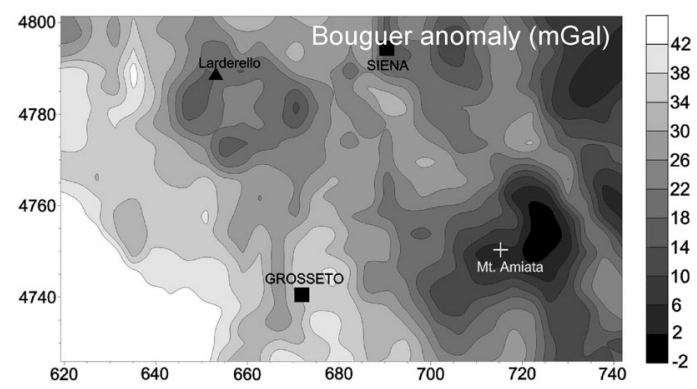

(b)

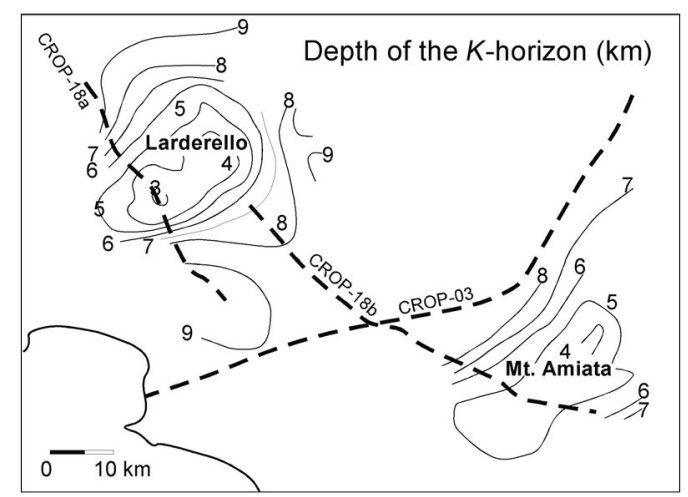

(C)

Fig. 3a-c. Maps showing (a) heat flow regime, b) Bouguer anomaly and (c) $K$-horizon depth.
2000). The geothermal fluids circulate through the larger fractures and faults, whose main orientation is the regional Apenninic one. Permeability is usually low and heterogeneously distributed. The results of many studies on contact metamorphic and hydrothermal minerals suggest that there were two main stages of hydrothermal activity: an early, high-temperature stage related to the intrusion of the granites, which produced contact metamorphic and metasomatic processes in the basement rocks, and a second stage characterised by precipitation of lower-temperature mineral assemblages filling veins at shallow-intermediate depths or, in certain places, replacing early-stage contact metamorphic or igneous minerals (Magro et al., 2003; and references therein). Since the structure is not widely fractured and the alteration minerals are localized around the faults and fractures, the alteration is not widespread.

Seismological studies have shown that the area extending from NE of Corsica to the inner part of the Northern Apennines is characterised by a thinned continental lithosphere and a large anomalous structure within the upper mantle (Gianelli et al., 1997; and references therein). The thin, elongated Tuscan Moho (depth $\sim 25$ $\mathrm{km}$ ) lies directly over a soft asthenosphere that has risen by $40-50 \mathrm{~km}$. The effects of this thinning and the subsequent magma intrusions at shallow depth are evident in the present heat flow regime, which shows a regional value of $120 \mathrm{~mW} / \mathrm{m}^{2}$ and higher values in the geothermal areas (fig. 3a). The thermal regime leads to a lower seismic velocity and density in the crust and in the upper mantle, as revealed by seismic tomography and gravity data (Batini et al., 1995; Bernabini et al., 1995). Minimum Bouguer values in the geothermal areas (fig. $3 b$ ), filtered for shallow structures and mantle effects, have been modelled as a roughly dropshaped low-density body between 7-8 and 20 $\mathrm{km}$ depth, and interpreted as shallow intrusive and still molten bodies (Bernabini et al., 1995; Fiordelisi et al., 1995). Seismic data provided valuable indications as to the shape and depth of the anomalous body in the Larderello region. Inversion of local earthquake arrival times and teleseismic travel-time residuals revealed the presence of a low velocity anomaly, $20 \mathrm{~km}$ 

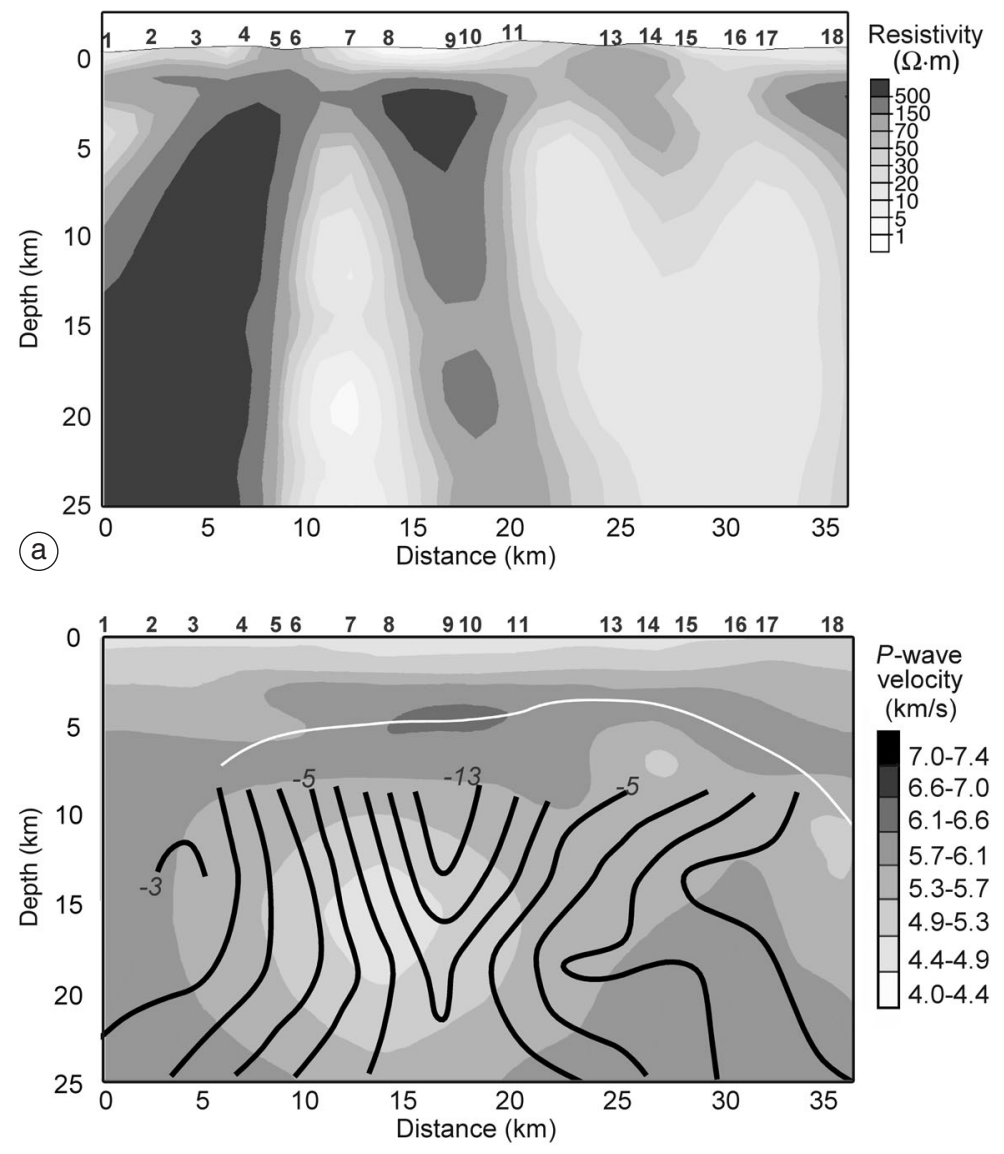

(b) Perturbation contour lines from teleseismic inversion $(\mathrm{km})$

Fig. 4a,b. a) 2D inversion results of the TM-mode MT data along $\mathrm{AA}^{\prime}$ profile in the Larderello area; b) local earthquake and teleseismic inversion results along the same profile (from Batini et al., 1995, modified).

wide at its top and possibly wider as it approaches the Moho, at depths of more than 8 $\mathrm{km}$ below ground level (see fig. 4a,b) (Batini et $a l ., 1995)$. A low velocity body was also identified below the Amiata area, but resolution here is much lower than at Larderello (Chiarabba et al., 1995). Another clue is provided by a seismic horizon, $K$, which was identified in the Amiata area and given the same name as the seismic horizon first observed at Larderello. Seismic reflectors having the same seismic signature as the $K$-horizon were recognised not on- ly in the geothermal fields of Larderello and Mt. Amiata, but also along the deep seismic reflection profiles CROP-03 and CROP-18 (e.g., Cameli et al., 1998). These horizons are often referred to as a single horizon, but this is not strictly true. The $K$-horizon locally shows «bright spot» features and is located at 3-4 km depth below the central parts of the geothermal fields of Larderello and Mt. Amiata, at 5-6 km depth along the margins of these same fields, and at $10-12 \mathrm{~km}$ depth outside the geothermal areas, where it becomes relatively flat. The 
form of the $K$-horizon shows many similarities with the heat flow and gravity maps (fig. 3c), rising sharply above the deep anomalous bodies defined by seismic tomography. The most common interpretation of this horizon is that it represents the brittle-ductile transition of the Tuscan crust, where fluid-filled fractures determine the bright-spot appearance in geothermal areas (Cameli et al., 1998; and references therein).

\section{Resistivity data and discussion}

Resistivity data have never achieved a decisive importance in Southern Tuscany. Due to the low resistivity of the shallower formations, the thousands of geoelectrical data acquired in the geothermal areas have never proved to be of real interest since they were able at most to define the resistivity distribution down to the resistive basement, whereas the main geothermal target for the past 30 years has been the deep reservoirs within the metamorphic basement. Moreover, due to the geological characteristics of the formations hosting the geothermal reservoirs in Tuscany and to their low permeability, geothermal fluid circulation does not produce a widespread alteration zone and the contribution to resistivity of very conductive clayey minerals can be neglected. Hence, the decrease in resistivity caused by thermal fluid circulation was not expected to be high, especially in the Larderello geothermal area, where the dominant fluid phase is steam.

The geoelectrical data acquired in the Larderello and Mt. Amiata areas, together with the results of a few resistivity logs in the Larderello area, and laboratory data (Losito, 1991), have been used to determine the resistivity values of the shallow geological units and to formulate hypotheses with regard to the deepest units. The shallow Neogenic deposits and Flysch units are electrically conductive (10-20 $\Omega \cdot \mathrm{m})$. The carbonate formations are only moderately resistive (usually around $100 \Omega \cdot \mathrm{m}$ ), whereas the anhydritic formations, interbedded with the carbonates, are occasionally very resistive, reaching values of $1000-1500 \Omega \cdot \mathrm{m}$. The resistivity of the metamorphic units measured in a few deep wells in the Larderello area are quite low (about $100 \Omega \cdot \mathrm{m}$ ) compared to those of the anhydrites and to the values measured on laboratory samples. This resistivity is probably representative of the upper, most fractured part of the metamorphic basement and a bulk value of many thousands of $\Omega \cdot \mathrm{m}$ is expected on the basis of the laboratory data, even accounting for the very high temperature and pressure conditions (Losito, 1991).

It is difficult to define the resistivity values in geothermal areas accurately because of the presence of geothermal fluids; by definition warm and salty, these fluids decrease the resistivity of the formations affected by fluid circulation. Formations that are usually resistive, such as metamorphic formations, in these conditions can assume values that are not so different from those of carbonatic formations. The presence of geothermal fluids also triggers dispersion phenomena over the frequencydependent MT sounding data (Stoyer, 1976; Patella, 1987). This is not a problem when many electrical sounding data are available, and comparison of the high-frequency MT data and the electrical data defining the shallower structures gives an idea of the dispersion rate (Patella et al., 1991). In our case, many electrical data were available in the Larderello and Amiata geothermal areas and the dispersion effect was found to be negligible. Outside the geothermal area the dispersion effect produced by hydrothermal fluid circulation is also probably negligible, as shown in Giammetti et al. (1996).

Looking at the distribution of sites in fig. 1 it is evident that most of the MT sites are distributed over profiles with a roughly WSWENE trend. This is because the main regional strike is defined by the Apenninic structure and the coast, i.e. ESE-WNW, and the profiles were designed orthogonal to the main strike. The profiles and the sparse sites are too widely separated to allow a 3D modelling of the MT data. Therefore, 2D interpretation of the data have been attempted. Depending on inductive and geological length scales of the target, 2D interpretation may provide useful information of the features of the subsurface, provided that near surface galvanic distortion are removed (Ledo et al., 2002). The MT data along the profiles 
shown in this paper have been modelled using a $2 \mathrm{D}$ inversion code, which use a regularized inversion algorithm that minimizes the sum of the chi-squared measure of data misfit and the squared norm of the Laplacian of the model function (Rodi and Mackie, 2001).

Since TM-mode data are less affected by complex effects caused by near 3D structures (Wannamaker et al., 1984; and references therein), we refer here to models obtained by inversion of TM-mode data only. Ledo et al. (2002) have discussed the applicability of this procedure and found results consistent with previous work, which suggest that the models obtained by inversion of TM-mode data only are more robust than those obtained using both polarization. However, the resistivity of the conductive $3 \mathrm{D}$ bodies is overestimated and the dipping structures are not well defined.

The MT data span a frequency range of about $300-0.001 \mathrm{~Hz}$, with some slight changes due to the different equipment used during fieldwork. The MT data considered in this study were acquired in the region after 1991. Before 1991 the data were acquired in the Larderello area as single-site or were referenced to a local site at a distance of, at most, $3 \mathrm{~km}$. The strong electromagnetic noise affecting the data for frequencies lower than $1 \mathrm{~Hz}$ cannot be separated from the MT signal in this case, and only shallow information can be gathered for these data (Fiordelisi et al., 1998).

The first MT data acquired in remote-reference mode and processed with robust algorithms were from Larderello, in 1992 (Fiordelisi et al., 1995). Two profiles, for a total of 34 sites at an average distance of $2 \mathrm{~km}$, crossed the main geothermal fields and the surrounding areas $\left(\mathrm{AA}^{\prime}\right.$ and $\mathrm{BB}^{\prime}$ in fig. 1). These data were recently reprocessed (Manzella et al., 2002) and the results obtained by $2 \mathrm{D}$ inversion of TM data on profile $\mathrm{AA}^{\prime}$ are shown in fig. 4a. The rms misfit of the model is 10.5 with a floor error of $5 \%$ and $2 \%$ for resistivity and phase, respectively. The modelling shows, on both profiles $\mathrm{AA}^{\prime}$ and $\mathrm{BB}^{\prime}$ (the latter is not shown here) that the area is characterized by many low resistivity anomalies. There is a good correlation between the most productive and exploited geothermal fields and the low resistivity anomalies.
The main anomalies show a very large vertical extension, and their location is comparable to those of the low seismic velocity anomalies defined by seismic tomography and described in Section 2 (fig. 4b). Since only TM-mode data were inverted, the resistivity of the anomalies is probably overestimated.

Unfortunately, the lateral and vertical extension of the anomalies, and hence of the reservoirs and their connection to deeper features, does not emerge in great detail since the distance between sites was quite large and the structure is very complex. The distance between MT sites was found to be of critical importance for defining the extension of these low resistivity areas. As an example, we consider two models obtained inverting the MT data acquired in the Mt. Amiata water-dominated geothermal area on 1994 (fig. 5a,b), along a profile named CC' in fig. 1 (Manzella et al., 1999). The model on the top was obtained by inverting the TM-mode MT data from just 26 sites at an average distance of $1 \mathrm{~km}$, and the one on the bottom by inverting the TM-mode MT data from 126 sites at an average distance of $200 \mathrm{~m}$ on the same profile. The rms misfit of the two models is 1.65 and 1.87 , respectively. The two models define very different features of the subsurface, in particular at large depth. The one on the bottom is probably a better and more detailed representation of the subsurface, taking into account, however, the limitation of the $2 \mathrm{D}$ interpretation of 3D structures. A spacing of just 1 $\mathrm{km}$ between MT sites is unable to resolve the lateral changes in resistivity occurring in an area with a sharp transition to lower resistivity, since this is caused by an abrupt increase in permeability through fractures and faults. The data, for the moment, are unable to predict the exact location and direction of the fractures at such great depths, which would be of considerable interest in geothermal exploration, but they identify the areas that are affected by deep circulation of geothermal fluids. The correspondence between areas of low resistivity inside the resistive basement and geothermal reservoirs is very evident in the Mt. Amiata waterdominated system, which was investigated by another continuous profiling survey, named $\mathrm{DD}^{\prime}$ in fig. 1 (Volpi et al., 2003). It is notewor- 

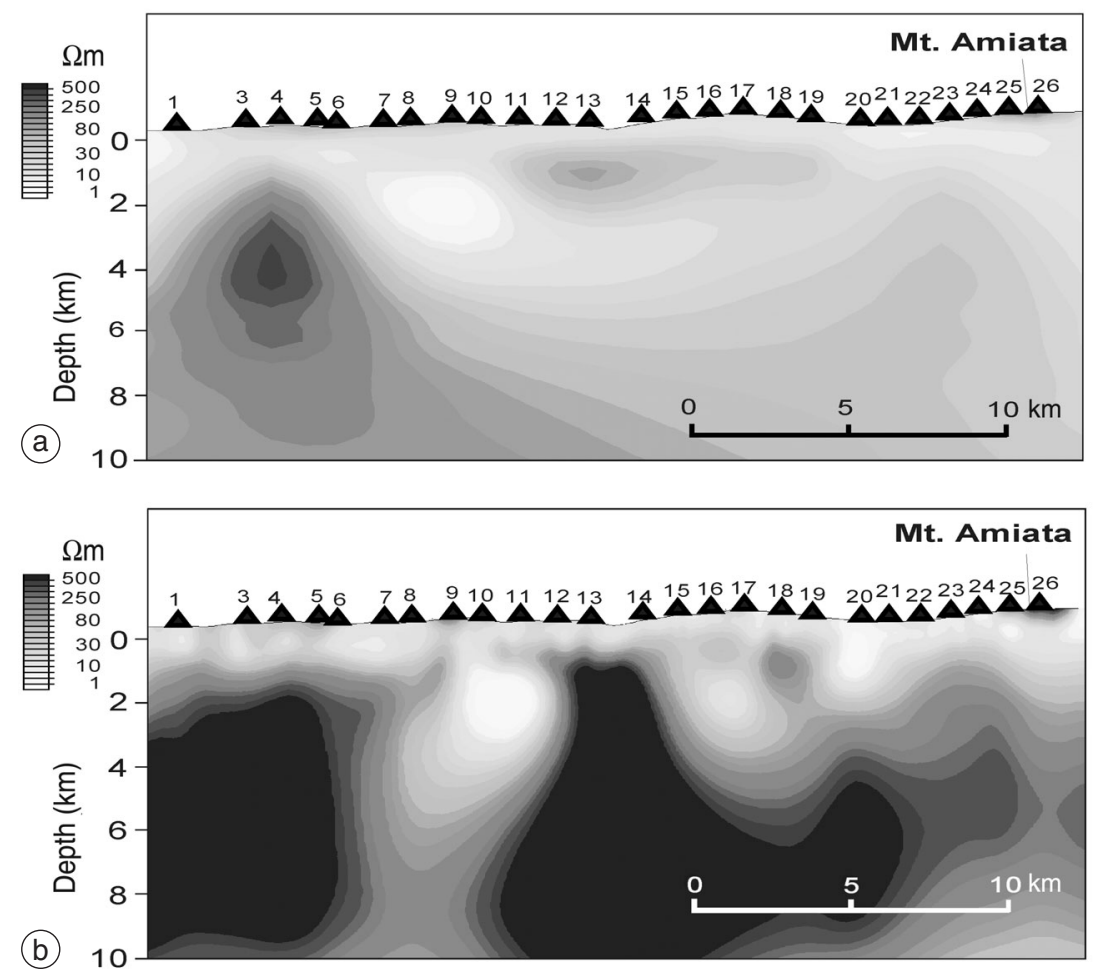

Fig. 5a,b. 2D inversion results in the Amiata area along profile $\mathrm{CC}^{\prime}$ : a) $\mathrm{TM}$ mode inversion of $26 \mathrm{MT}$ sites along a profile; b) TM mode inversion of 126 sites along the same profile.

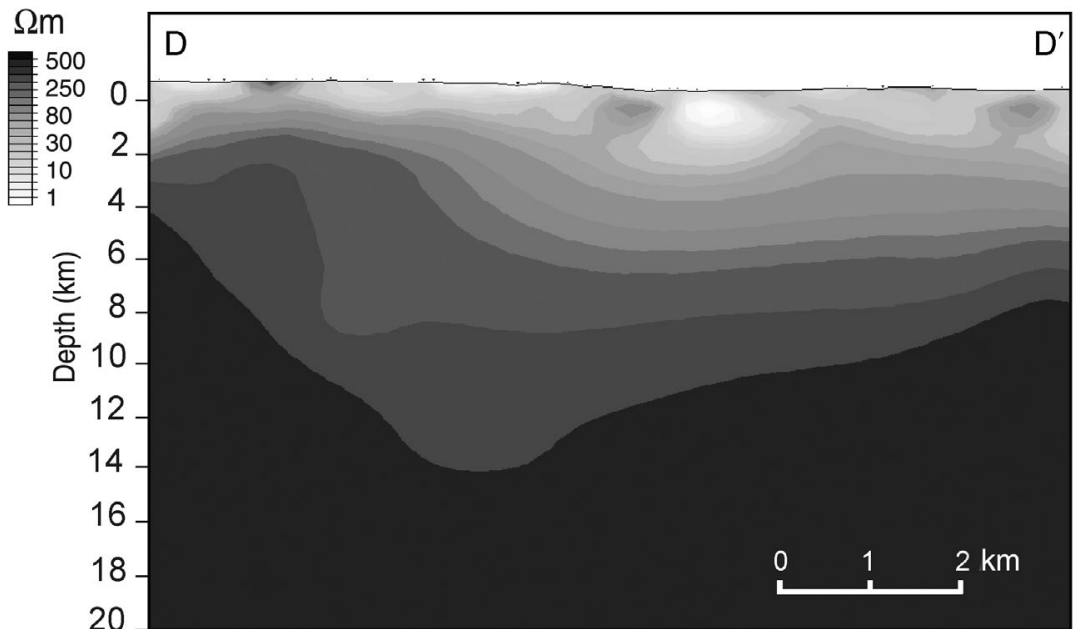

Fig. 6. $2 \mathrm{D}$ inversion results in the Amiata area along profile $\mathrm{DD}^{\prime}$. 
thy that, below the Mt. Amiata exploited geothermal area, the resistivity is never as low as in Larderello at a depth of more than 7-8 km (figs. $5 \mathrm{a}, \mathrm{b}$ and 6). The main decrease in resistivity, comparable to that of some sites in the Larderello area, is found outside the geothermal area, about $15 \mathrm{~km} \mathrm{SW}$ of Mt. Amiata.

Apart from the surveys in geothermal areas, MT data were also acquired within the framework of deep crustal exploration projects. Although many of these data are too affected by noise to be of any use, some proved to be good and were considered in this study. The profile $\mathrm{EE}^{\prime}$ in fig. 1 included many sites where noise was absent or very low (De Angelis et al., 1998). The model obtained by 2D forward modelling is shown in fig. 7, and depicts a continuous increase of resistivity with depth. Despite the clear limitation of the 2D model where the sites have an average distance of $10 \mathrm{~km}$, it is evident from the figure that the most conductive formations, with resistivity lower than $50 \Omega \cdot \mathrm{m}$, are confined to depths of less than $2-3 \mathrm{~km}$. The only exceptions to this general trend occur near the eastern border of the model, with an uplift of the Tuscan Nappe that appears reversed at the surface, and below the outcropping volcanics (site 11 in fig. 7), where the resistive layer rises to a depth of about 8-9 km. This shallow resistive body was interpreted as an intrusion of hot material that rose in the past and cooled completely.

Other data, acquired on sites located $20 \mathrm{~km}$ west of Mt. Amiata, show a very low, deep resistivity that is comparable only to that of some sites in the Larderello area and SW of Mt. Amiata (Manzella and Fiordelisi, 1995).

In general we observe that MT data can be divided into three main categories, which are named only for representation purposes: 1) normal sites, located outside the geothermal area, whose apparent resistivity at frequencies lower than $10^{-2} \mathrm{~Hz}$ (i.e. at greater depths) is higher than $100 \Omega \cdot \mathrm{m} ; 2$ ) deep, low resistivity sites, characterized by an apparent resistivity lower than $10 \Omega \cdot \mathrm{m}$ at frequencies lower than $10^{-2} \mathrm{~Hz}$; and 3 ) geothermal sites, located in intensely exploited geothermal areas, whose apparent resistivity at lower frequencies is lower than in normal sites but higher than in low resistivity sites.

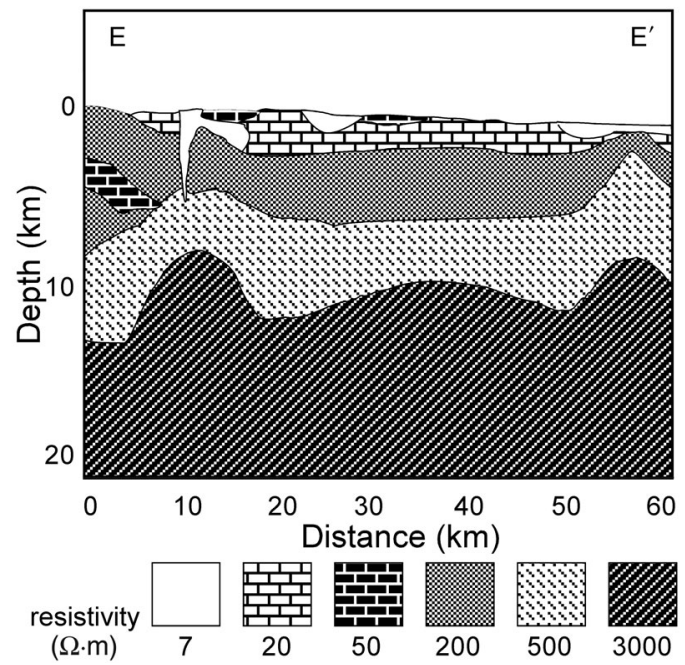

Fig. 7. 2D forward modelling results along profile $\mathrm{EE}^{\prime}$.

The geographical distribution of the three types of sites is shown in fig. 8, as well as a sample curve for each of the three categories. Comparing fig. 8 with fig. $3 \mathrm{a}$, we observe that the areas where the heat flow values are highest do not always correspond to the areas with the lowest resistivity below $8-10 \mathrm{~km}$ depth. The low resistivity data in the Larderello area show a good correspondence both with the maximum heat flow values and the location of the low velocity anomaly defined by seismic tomography. This evidence, together with other geophysical and geological information described in Section 2, can be interpreted as due to the presence of a still hot and partially molten magmatic body, representing the heat source of the Larderello geothermal area. With the actual data it is impossible to say whether there is one, large magmatic body only or many different bodies, possibly interconnected. Geochemistry has shown that the helium values at Larderello are anomalous, suggesting a mantle origin for part of the geothermal fluids, and hence depicting a direct connection of the magmatic body/-ies with the upper mantle (Magro et al., 2003). With the data available at present, however, we are unable to verify this hypothesis. 


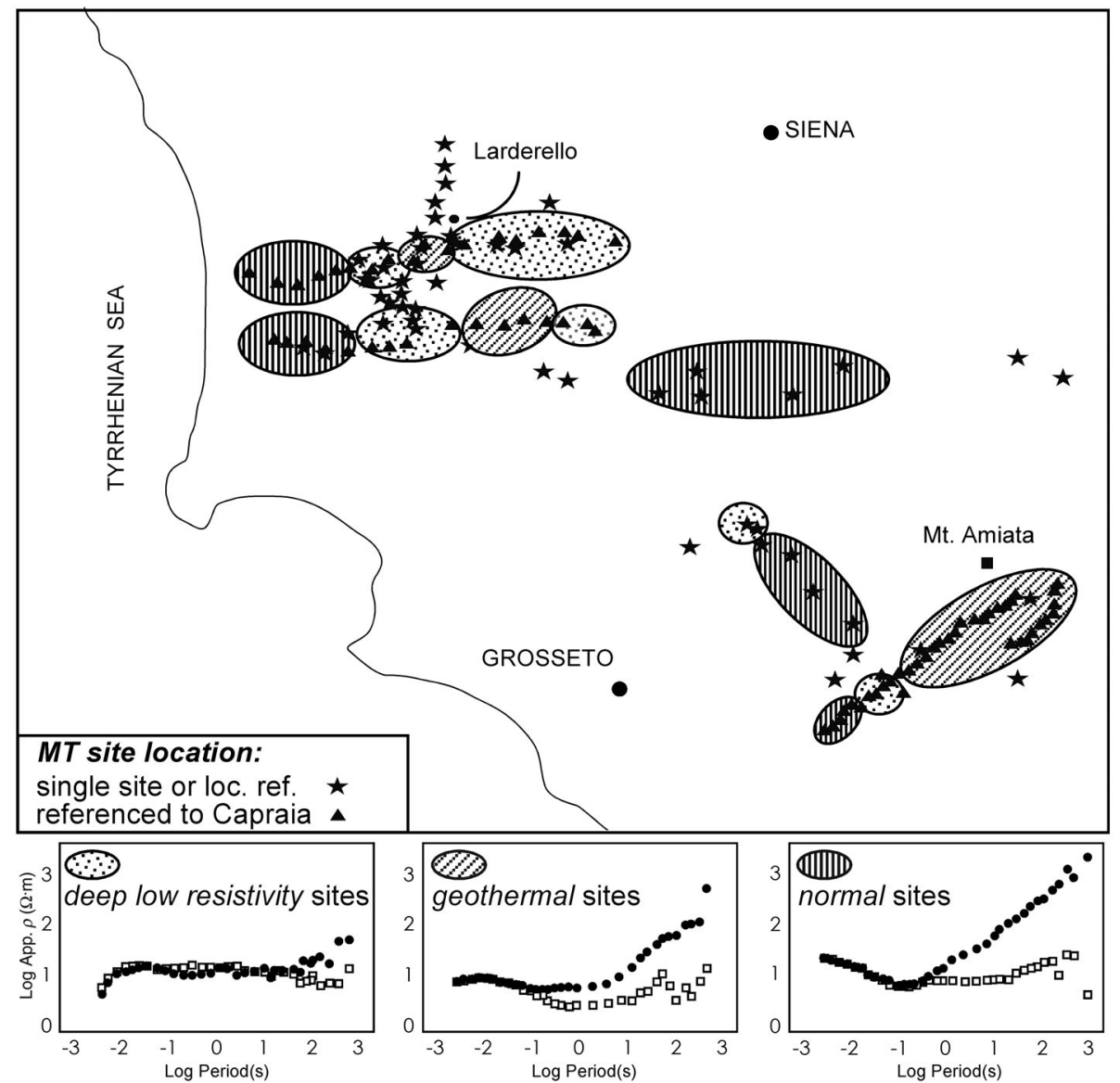

Fig. 8. Distribution of the three main categories of MT sites (see text): dotted ovals indicate areas of very low deep resistivity (few $\Omega \cdot \mathrm{m}$ ); slashed ovals correspond to areas of average deep resistivity (100-200 $\Omega \cdot \mathrm{m}$ ) and densely lined ovals indicates areas of high deep resistivity $(1000-2000 \Omega \cdot \mathrm{m})$. An example curve of the three main categories of sites is given on the bottom.

Although its reservoir temperatures can be as high as $320^{\circ} \mathrm{C}$, the Amiata area appears quite different from Larderello. Both the MT and the seismic data are unable to identify any clear reduction in resistivity and seismic velocity below this area. This difference with the situation at Larderello could be explained by assuming that the magmatic body is deeper and maybe smaller than at Larderello. Nor does the geochemistry show any evidence of a mantle origin in the geothermal fluids, so the difference could also be due to a different connection with deeper crustal and mantle structures.

Fifteen kilometres SW of Amiata we identified an area with deep, low resistivity and no apparent relation to the Amiata area itself (Manzella et al., 1999). This area also shows an increase in heat flow values, but no seismic tomography data are available. In the other area with low resistivity at depth, located $20 \mathrm{~km}$ west of Mt. Amiata, neither heat flow nor seismic tomography data are available for comparison. 
Magmatic bodies could be present below these areas, at depths similar to those at Larderello, but have never been identified before because of a lack of surface manifestations.

The general behaviour of resistivity in the medium crust is another matter of some interest here. Many papers report a decrease of resistivity in the medium-deep crust, which was interpreted as being linked to the transition from brittle, shallow to ductile, deep conditions, and, possibly, the presence of fluids (see, e.g., Simpson, 1999; and references therein). A region such as Southern Tuscany, so richly endowed in geothermal fluids, some of which are of deep origin, should be a perfect example of how deep crustal fluids can affect resistivity. As already mentioned in Section 2, the brittle-ductile transition in this region is possibly evidenced by the seismic marker $K$ and it probably follows the same shape of the $K$-horizon «surface» shown in fig. 3c at a slightly different depth. Hence, the transition was definitely explored by the MT data described in this study, since it is quite shallow. Indeed, no evidence of a decrease of resistivity can be seen at depths corresponding to the ductile condition of the crust.

\section{Conclusions}

The MT data show evidence of an extremely heterogeneous distribution of crustal resistivity in Southern Tuscany. MT penetration depths of more than $4 \mathrm{~km}$ were achieved only where electromagnetic noise was absent, or could be eliminated. In general, the MT data show that below this depth the resistivity reaches values of only a few thousands of $\Omega \cdot \mathrm{m}$, which is far lower than in metamorphic formations in other parts of the world. This is not unusual, however, for a tectonically active area such as Southern Tuscany, where the high reflectivity and the high heat flow could indicate the presence of fluids and/or melts on a fairly wide scale. Besides the resistivity anomalies created by local conditions at depths of 2-5 km, the MT data also reveal that the resistivity distribution is not homogeneous below 8-10 km depth, and that low resistivity subsurface does not show a simple relation to the heat flow distribution.
The deep, low resistivity anomalies were found below the geothermal area of Larderello and in areas located west and south-west of the Amiata area but outside the main geothermal area, whereas deep resistivity in the central Amiata area has been observed to increase. The MT data seem to indicate that the intrusions lie at greater depth in the Amiata area than in the Larderello area, and that intrusions comparable to those at Larderello may be present in areas that have still to be explored. The connections at depth between these many magmatic bodies has still to be investigated. A clear transition to low resistivity in the medium and deep crust is absent in Southern Tuscany, suggesting that the effects of temperature and fluid distribution do not depend on the transition to ductile conditions.

More MT data are needed to obtain a clearer picture in the region. Future experiments will include the acquisition of data at lower frequency than have been acquired till now, and longer recordings in order to obtain a better quality.

\section{Acknowledgements}

The author thanks Enel and the COFIN2000 Project for providing data and for partly funding this research, and Marnell Dickson for proof-reading the original manuscript.

\section{REFERENCES}

Barelli, A., G. Bertini, G. Buonasorte, G. Cappetti and A. FIORDELISI (2000): Recent deep exploration results at the margins of the Larderello Travale geothermal system, in Proceedings of the World Geothermal Congress 2000, Kyushu-Tohoku, Japan, 965-970.

Batini, F., A. Fiordelisi, F. Graziano and M.N. ToKSOZ (1995): Earthquake tomography in the Larderello geothermal area, in Proceedings of the World Geothermal Congress 1995, Firenze, Italy, 817-820.

Bernabini, M., G. Bertini, G.M. Cameli, I. Dini and L. ORLANDO (1995): Gravity interpretation of Mt. Amiata geothermal area (Central Italy), in Proceedings of the World Geothermal Congress 1995, Firenze, Italy, 859-862.

Cameli, G.M., I. Dini and D. LiotTA (1998): Brittle/ductile boundary from seismic reflection lines of Southern Tuscany (Northern Apennines, Italy), Mem. Soc. Geol. It. , 52, 153-163.

ChiarabBa, C, A. Amato and A. Fiordelisi (1995): Seismicity and velocity images of the Roman Magmatic 
Province, in Proceedings of the World Geothermal Congress 1995, Firenze, Italy, 827-832.

De Angelis, M. A. Fiordelisi, A. ManZella and A. Zaja (1998): Two-dimensional analysis of a magnetotelluric profile in the CROP 03 area in Southern Tuscany, Mem. Soc. Geol. It., 52, 295-304.

Fiordelisi, A., R. Mackie, T. Madden, A. Manzella and S. RIEVEN (1995): Application of the magnetotelluric method using a remote-remote reference system for characterizing deep geothermal system, in Proceedings of the World Geothermal Congress 1995, Firenze, Italy, 893-898.

Fiordelisi, A. R. MACKie, A. Manzella and A. Zaja (1998): Electrical features of deep structures in Southern Tuscany (Italy), Ann. Geofis., 41 (3), 333-341.

Fiordelisi, A., A. Manzella, G. Buonasorte, J. Larsen and R. MACKIE (2000): MT methodology in the detection of deep, water-dominated geothermal systems, in Proceedings of the World Geothermal Congress 2000, Kyushu-Tohoku, Japan, 1121-1126.

Giammetti, S., D. Patella, A. Siniscalchi and A. TraMACERE (1996): The Siena Graben: combined interpretation of DES and MT soundings, Ann. Geofis., XXXIX (1), 189-200.

Gianelli, G., A. Manzella and M. Puxeddu (1997): Crustal models of the geothermal areas of Southern Tuscany (Italy), Tectonophysics, 281, 221-239.

Larsen, J.C., R.L. Mackie, A. Manzella, A. Fiordelisi and S. RIEVEN (1996): Robust smooth magnetotelluric transfer functions, Geophys. J. Int., 124, 801-819.

Ledo, J., P. Queralt, A. Martí and G. Jones (2002): Twodimensional interpretation of three-dimensional magnetotelluric data: an example of limitations and resolution, Geophys. J. Int., 150, 127-139.

Losito, G. (1991): Proprietà elettriche delle rocce lungo il profilo CROP 03, Studi Geologici Camerti, 1, 33-40.

Magro, G., G. Ruggieri, G. Gianelli and S. Bellani (2003): Helium isotopes in paleofluids and present-day fluids of the Larderello geothermal field: constraints on the heat source, J. Geophys. Res., 108 (B1), doi:
10.1029/2001JB001590.

Manzella, A. and A. Fiordelisi (1995): Resistivity structure on the western side of the Mt. Amiata region, in Proceedings of the World Geothermal Congress 1995, Firenze, Italy, 881-886.

Manzella, A., R. Mackie and A. Fiordelisi (1999): MT survey in the Amiata volcanic area: a combined methodology for defining shallow and deep structures, Phys. Chem. Earth, A, 24 (9), 837-840.

Manzella, A., G. Volpi, F. Corsi and A. Fiordelis (2002): Distribution of resistivity in the upper crust of the Larderello geothermal area, in Studi per l'Interpretazione del Profilo Sismico CROP18, II Stato di Avanzamento, 16-24.

Patella, D. (1987): Tutorial: interpretation of magnetotelluric measurements over an electrically dispersionale one-dimensional Earth, Geophys. Prospect., 35, 1-11.

Patella, D., A. Tramacere, R. Di Maio and A. SinisCALCHI (1991): Experimental evidence of resistivity frequency-dispersion in magnetotellurics in Newbury (Oregon), Snake River Plain (Idaho) and Campi Flegrei (Italy) Volcano-geothermal areas, J. Volcanol. Geotherm. Res., 48 (1-2), 61-75.

RodI, W. and R.L. MACKIE (2001): Nonlinear conjugate gradients algorithm for 2D magnetotelluric inversion, Geophysics, 66, 174-187.

SiMPSON, F. (1999): Stress and seismicity in the lower continental crust: a challenge to simple ductility and implications for electrical conductivity mechanisms, Surv. Geophys., 20 (3-4), 2001-227.

Stoyer, C.H. (1976): Consequences of induced polarization in magnetotelluric investigation, Pure Appl. Geophys., 114, 435-449.

VolPi, G., A. MANZElla and A. Fiordelisi (2003). Investigation of geothermal structures by magnetotelluric (MT): an example from the Mt. Amiata area, Italy, $G e$ othermics, 32 (2), 131-145.

Wannamaker, P., G. Hohmann and S. Ward (1984): Magnetotelluric responses of three-dimensional bodies in layered earths, Geophysics, 49, 1517-1533. 